\section{Banting, Fredrick Grant}

\section{W. Hubl}

Ehem. Krankenhaus Dresden-Friedrichstadt, Institut für Klinische Chemie und Labormedizin, Dresden, Deutschland

Lebensdaten Geboren 14. November 1891 in Alliston (Ontario, Kanada), gestorben 21. Februar 1941 auf Neufundland (Flugzeugabsturz). Zunächst Studium der Theologie, dann Wechsel zum Medizinstudium; 1916 Promotion an der Universität von Toronto; 1921 gemeinsam mit Charles Best Isolierung von Pankreasextrakten zur Behandlung von Dia- betes mellitus; 1923 Professur an der Universität von Toronto; 1932 Gründung des Banting-Best-Institutes.

Verdienste Gemeinsam mit Charles Best Entdecker des Insulins. 1923 erhielt Banting gemeinsam mit John James Richard MacLeod den Nobelpreis für Medizin „Für die Entdeckung des Insulins“. Banting teilte das Preisgeld mit Charles Best.

\section{Literatur}

Eckart WU, Gradmann C (2006) Ärzte Lexikon - Von der Antike bis zur Gegenwart, 3. Aufl. Springer, Berlin/Heidelberg/New York, S 26 